\title{
Analysis on the Contribution of R\&D Input to Economic Growth in Western China
}

\author{
Fei hang Wang ${ }^{1,}$, , Ming fei liü,b \\ ${ }^{1}$ Economics School ,Lanzhou University ,Lanzhou ,Gansu ,China 730000 \\ ${ }^{2}$ Economics and Management School ,Lanzhou University of Technology , Lanzhou ,Gansu ,China \\ 730050 \\ afhwang@126.com, b1592210205@qq.com
}

\begin{abstract}
Key words: science and technology input; economic growth; industrial structure
Abstract: The paper used the extended C-D production function, and made an analysis on panel data of Western China's 12 regions during the period from 2000 to 2015 ,caculated the R\&D input to economic growth. The research shows that there are large diffirences among the diffirent regions.In Western China, R\&D input has played a catalytic role to economic growth only in eight areas.Put forward the some suggestiont.Strengthen the R\&D investment, change the mode of economic development, and rationally arrange the investment of resources.
\end{abstract}

\section{Introduction}

R\&D means the systematic creative work in order to increase the total amount of knowledge and apply knowledge to create new applications. R\&D input is the main factor in science and technology innovation activities and China's economic transformation.It is the necessary condition and foundation to guarantee the science and technology development.

During three decades of rapid economic growth after the Reform an Opening -up, the difference between the eastern and western regions has gradually increased due to the national policies influence and economic condition limit.After entering 21st Century, China has implemented the great strategy of developing the western regions, and the western region has made rapid economic development by its own advantages.Compared with the Eastern China, there is still a large gap in economic growth,which is bad for the steady economic development in China.Scientific and technological progress to promote economic growth is critical path to achieve rapid and sustainable economic development in the western China, as well as the key to make the innovation-oriented country.Scientific and technological progress and R\&D input are not separable.Therefore, it is necessary to study the lationship between $\mathrm{R} \& \mathrm{D}$ input and the economic growth in Western China.,with the hope that doing so will bring some enlightenment and reference to the Western China.

\section{Literature References}

$\mathrm{R} \& \mathrm{D}$ is a source in science and technology progress.In 1928, Economics professor Douglas and mathematician Cobb in Chicago University put forward the Cobb-Douglas production function, to explore the relationship between input and output, but the function is unable to quantitatively analyze the effect of technical progress[1].In 1957, Solow calculated contribution rate of technical progress on economic growth, but he regarded technological progress as an exogenous variable[2]. 1980s, economists Romer and Lucas put forward a new economic growth theory, regarding technological progress as the endogenous variable to promoting economic growth, which 
considered technical progress as an important factor for economic growth[3,4].Trajtenberg and Fogarty (2000) believe that R\&D investment will promote technological progress and improve labor productivity in the industry[5].Rajeev K.Goe (2008), by collecting of 1953-2000 years of R\&D investment and economic development data in the United States, analyzed the role of R\&D investment in economic growth, and he pointed out the importance of R\&D investment to economic development[6].

Scholars have applied various methods to study the contribution of R\&D input,whose results are remarkable.The development of Western China has its unique characteristics.Therefore, the article uses the method of quantitative analysis to calculate the contribution of $R \& D$ input in western China to economic growth.Provide suggestions for government decision-making and promote the economic development of the western China.

\section{Model establishment and data sources}

Economic model building. There are many methods to study contribution of R\&D input to economic growth. In addition to R\&D input,capital input and labor input are the factors that can't be ignored .Therefore, the paper selects the following Cobb-Douglas production function:

$$
Q=A K^{\alpha} L^{\beta} R^{\gamma}
$$

In order to correct the heteroscedasticity and study the differences among the western regions ,take logarithm on both sides. The model is revised to:

$$
\ln Q_{i t}=c_{i}+\alpha_{i} \ln K_{i t}+\beta_{i} \ln L_{i t}+\gamma_{i} \ln R_{i t}+\mu_{i t}
$$

In the formula , $\mathrm{C}$ is the intercept term. $\mathrm{Q}$ is the total output, $\mathrm{K}$ is capital input, $\mathrm{L}$ is labor input, and $R$ is $R \& D$ input.$i$ is each region.t is time . $\mu$ is random disturbance $. a, \beta, \gamma$ are the output elasticity corresponding to each variable.

In the related research, the total output Q is generally expressed by GDP, so in this paper Q is expressed by the gross output value (GDP) of the western region in China .K is the fixed assets investment in the western regions over the years.$R$ is the $R \& D$ investment for each region.

sample data description. All of the raw data are quoted from China Statistical Yearbook(20012016), as well as China Statistical Yearbook of science and Technology"(2001-2016), and the The Statistics Bureau official website in various regions.

Table 1 descriptive statistics of sample data

\begin{tabular}{lllll}
\hline Variable & Mean & Maximum & Minimum & Standard \\
\hline $\ln Q$ & 8.0383 & 10.3107 & 4.7690 & 1.2001 \\
$\ln \mathrm{C}$ & 7.5867 & 10.1648 & 4.1672 & 1.3225 \\
$\ln \mathrm{C}$ & 7.0351 & 8.4861 & 4.8217 & 0.9887 \\
$\ln \mathrm{R}$ & 2.9887 & 6.2203 & -1.6064 & 1.6753 \\
\hline
\end{tabular}

Descriptive statistics show that the standard deviation is relatively less, indicating that the data stability is better in table 1 .

\section{Empirical analysis on the effect of R\&D input to economic growth}

Unit root test.In order to aviod spurious regression produced by the unsteady economic variables, it requires unit root test before regression. The usual inspection methods are LLC test, IPS test, ADF-Fisher test, PP-Fisher test.The paper uses Eviews7.2 to test each variable of panel data, and the result is as follows: 
Table 2 Unit root test results of panel data (1)

\begin{tabular}{llllll}
\hline Variable & LLC & IPS & ADF-Fisher & PP-Fisher & Is it stationary? \\
\hline $\ln Q$ & $-3.21446^{* * *}$ & 2.13871 & 13.4441 & 11.7320 & Non-stationary \\
$\ln K$ & $-2.67730^{* * *}$ & 2.86226 & 10.5280 & 9.02125 & Non-stationary \\
$\ln L$ & 5.32244 & 5.89586 & 8.85523 & 10.5117 & Non-stationary \\
$\ln R$ & $-4.7455^{* * *}$ & 0.86109 & 18.8695 & 15.7743 & Non-stationary \\
\hline
\end{tabular}

Table 3 Unit root test results of panel data (2)

\begin{tabular}{llllll}
\hline Variable & LLC & IPS & ADF-Fisher & PP-Fisher & Is it stationary? \\
\hline$\Delta \ln Q$ & $-3.88351^{* * *}$ & $-2.94216^{* * *}$ & $46.9451^{* * *}$ & $45.3698^{* * *}$ & First-order stationary \\
$\Delta \ln K$ & $-3.32240^{* * *}$ & $-3.56008^{* * *}$ & $53.5038^{* * *}$ & $52.3421^{* * *}$ & First-order stationary \\
$\Delta \ln L$ & $-8.35376^{* * *}$ & $-6.12340^{* * *}$ & $79.6087^{* * *}$ & $84.5642^{* * *}$ & First-order stationary \\
$\Delta \ln R$ & $-7.07150^{* * *}$ & $-6.79178^{* * *}$ & $102.455^{* * *}$ & $141.500^{* * *}$ & First-order stationary \\
\hline
\end{tabular}

Co-integration test. According to the results of unit root test in table 2 and table 3 , the $\ln$, $\operatorname{lnK}, \operatorname{lnL}, \ln R$, variables are first-order stationary, which shows that there may be some co-integration relationships among them .The co-integration test results are as follows:

Table 4 co-integration test of panel data

\begin{tabular}{lcllllll}
\hline Statistic & $\begin{array}{c}\text { Panel } \\
\text { v-stat }\end{array}$ & $\begin{array}{l}\text { Panel } \\
\text { rho- stat }\end{array}$ & $\begin{array}{l}\text { Panel } \\
\text { pp-stat }\end{array}$ & $\begin{array}{l}\text { Panel } \\
\text { ADF-stat }\end{array}$ & $\begin{array}{l}\text { Group } \\
\text { rho-stat }\end{array}$ & $\begin{array}{l}\text { Panel } \\
\text { pp-stat }\end{array}$ & $\begin{array}{l}\text { Panel } \\
\text { ADF-stat }\end{array}$ \\
\hline $\begin{array}{l}\text { Test } \\
\text { result }\end{array}$ & -0.6448 & 1.3463 & $-1.2666^{*}$ & $-2.0011^{* *}$ & 2.7931 & $-2.7903^{* * *}$ & $-2.1843^{* * *}$ \\
\hline
\end{tabular}

There is a panel co-integration relation , as well as long-term equilibrium relationship in table 4.

Panel model estimation. There are three kinds of models: variable intercept model, variable coefficient model and mixed estimation model. The model form must be determined by hypothesis testing:

Establish two hypotheses:

$\mathrm{H}_{0}$ :The member variable coefficients of the cross section are equal, and the intercept terms are different.

$\mathrm{H}_{1}$ :The member variable coefficients and the intercept terms are equal.

Set the following two statistics:

$$
\begin{gathered}
F_{1}=\frac{\left(S_{2}-S_{1}\right) /(N-1) K}{S_{1} /[N T-N(K+1)]} \sim F[(N-1) K, N T-N(K+1)] \\
F_{2}=\frac{\left(S_{3}-S_{1}\right) /[(N-1)(K+1)]}{S_{1} /[N T-N(K+1)]} \sim F[(N-1)(K+1), N T-N(K+1)]
\end{gathered}
$$

If $\mathrm{H}_{1}$ is not rejected, the estimation model being a mixed model. If $\mathrm{H}_{1}$ is rejected, then verify the hypothesis $\mathrm{H}_{0}$.If $\mathrm{H}_{0}$ is rejected ,it is a variable coefficient mode .On the contrary, it is a variable intercept model. 
Table 5 covariance test results of panel data

\begin{tabular}{lll}
\hline Sum of squares of residuals & F statistic & critical value \\
\hline $\mathrm{S}_{1}=1.5451$ & $\mathrm{~F}_{1}=2.3567$ & $\mathrm{~F}_{1}(33,144) \approx 1.675$ \\
$\mathrm{~S}_{2}=2.1009$ & $\mathrm{~F}_{2}=11.8167$ & $\mathrm{~F}_{2}(44,144) \approx 1.571$ \\
$\mathrm{~S}_{3}=7.1188$ & & \\
\hline
\end{tabular}

According to the results in table 5, the statistic values of $F_{1}$ and $F_{2}$ are bigger than the critical value of $\mathrm{F}$ distribution at $5 \%$ level, rejecting $\mathrm{H}_{0}$ and $\mathrm{H}_{1}$, so the variable coefficient model should be adopted.

The influence form of panel data model can be divided into fixed effects and random effects. In this paper, Hausman test is used to determine the model form .The Hausman statistic is 35.8902 and the $\mathrm{P}$ value is 0.000 .Therefore, the fixed effect model should be used. The paper chooses the fixed effect variable coefficient model and uses Eviews7.2 to estimate, and the measurement results are as follows:

Table 6 estimation results of fixed effects variable coefficient model

\begin{tabular}{lcccccc}
\hline \multirow{2}{*}{ Province } & \multicolumn{2}{c}{ LnK } & \multicolumn{2}{c}{ LnL } & \multicolumn{2}{c}{ LnR } \\
\cline { 2 - 7 } Inner & Coefficient & t value & coefficient & t value & coefficient & t value \\
Mongolia & 0.117 & $3.665^{* * *}$ & -0.430 & $-7.205^{* * *}$ & 0.602 & $20.698^{* * *}$ \\
Guangxi & 0.666 & $10.398^{* * *}$ & -0.799 & $-2.338^{* *}$ & -0.013 & -0.201 \\
Chongqing & 0.348 & $10.954^{* * *}$ & 0.915 & $15.368^{* * *}$ & 0.321 & $11.045^{* * *}$ \\
Sichuan & 0.374 & $17.569^{* * *}$ & 14.855 & $12.649^{* * *}$ & 0.160 & $5.929^{* * *}$ \\
Guizhou & 0.549 & $15.470^{* * *}$ & -0.664 & $-6.802^{* * *}$ & 0.188 & $4.459^{* * *}$ \\
Yunnan & 0.323 & $7.661^{* * *}$ & 3.298 & $9.686^{* * *}$ & 0.037 & 0.931 \\
Tibet & 0.494 & $17.713^{* * *}$ & 0.616 & $3.966^{* * *}$ & 0.137 & $7.993^{* * *}$ \\
Shanxi & 0.871 & $29.891^{* * *}$ & -0.239 & -1.447 & -0.227 & $-4.908^{* * *}$ \\
Gansu & 0.373 & $13.513^{* * *}$ & -0.933 & $-5.746^{* * *}$ & 0.358 & $10.419^{* * *}$ \\
Qinghai & -0.006 & -0.089 & 13.551 & $8.635^{* * *}$ & 0.268 & $7.703^{* * *}$ \\
Ningxia & 0.071 & 0.374 & -1.400 & -0.776 & -0.713 & $3.492^{* * *}$ \\
Xinjiang & 0.366 & $3.636^{* * *}$ & 0.166 & 0.518 & 0.275 & $5.451^{* * *}$ \\
\hline
\end{tabular}

Except Guangxi and Yunnan, R\&D input plays a significant role in economic growth in Table 6.The R\&D input in Shaanxi and Ningxia is negatively related to economic growth , the other is promting the economic growth. The biggest promoting effect is in Inner Mongolia . When R\&D input increases by $1 \%$, GDP increases by $0.602 \%$.Others are between 0.137 and 0.358 .

\section{conclusions}

(1)In the most western regions ,the R\&D input has a long-term and effective impact on economic growth .The phenomenon is consistent with Romer's endogenous economic growth theory .It is that knowledge production departments can promote technological progress , and increasing R\&D funding will promote economic growth, ultimately promoting GDP .Due to the differences in the western region, the development characteristics of each region are different, so the input-output efficiency of $R \& D$ is also different .Increasing $R \& D$ input is still the direction to improve the level of economic development in the future.

(2) R\&D input dose not plays a significant role in economic growth in Yunnan and Guangxi .In Shaanxi and Ningxia it is negatively related to economic growth .One possibility is that R\&D input in the western regions has exceeded the optimal scale that promote economic growth, the other is 
probably that there are a large number of intensive labor enterprises .At the same time, the lack of scientific and technological personnel for researching new products has led to a decline in R \& D input-output efficiency.

(3)The input-output efficiency of Western China is $11.608 \%$,lower than the eastern region .As China has implemented the strategy of developing the western region in recent years, it has been increasing the investment, and this result is not satisfactory.

Therefore, the following suggestions are put forward:

First, R\&D input plays a significant role in promoting economic growth, and continuing to increase it has great significance to transform the mode of economic growth .Increasing R\&D input is still the direction to improve the level of economic development in the future .While increasing the R\&D input ,the government should allocate resources reasonably according to the development characteristics of each region and the contribution of R\&D output.

Second, change the mode of economic development .For areas where R\&D input has no positive effect, the government should strengthen investment in leading enterprises or emerging enterprises that have better development momentum . To make enterprises from labor-intensive to technology intensive and strengthen the input of knowledge output department.

Third, about inefficient production in Western China, the government should rationally allocate resources in basic research and applied research, undertake more basic research tasks, and guide enterprises and private funds to actively participate in scientific and technological activities, which is to improve the efficiency of the allocation of resources rather than just increase input.

\section{References}

[1]Cobb C W, Douglas P H. A theory of production [J]. American Economic Review, 1928(1): $139-165$.

[2]Solow R M. Technical change and the aggregate production[J].Review of Economics and Statistics, 1957(3): $312-320$.

[3] Lucas, R. E. On the Mechanics of Economic Development[J]. Journal of Monetary Economics 22, 1988: 3-42.

[4] Romer, Paul. Increasing Returns and Long-Run Growth[J]. Journal of Political Economy 94,1986: 1002-1037.

[5] Griliches Z. Productivity ,R\&D and Basic Research at the Firm Level in the 1970s [J].American Economic Review, 1986, vo1.76 (June).

[6]Rajeev K .Gole ,James E. Payne ,Rati ,Ram .R\&D expenditures and U.S. Economic grows :A disaggregated approach[J].Technological Forecasting and Social Change,2006,73(4):452-465. 